\title{
The Preparation of $\beta$ Sialon from Kaolin by Carbonitrothermic Reduction
}

\author{
F.S. Cinar, J.C.T. Van der Heijde*, R.A. Terpstra* and A. Tekin \\ Faculty of Chemistry and.Metallurgy, Istanbul Technical University, \\ 80626 Maslak, Istanbul, Turkey \\ *Center for Technical Ceramics, TNO/Eindhoven University of Technology, \\ P.O. Box 513, 5600 MB Eindhoven, The Netherlands
}

\begin{abstract}
The preparation of $\beta$-sialon from Turkish kaolin by carbothermic reduction under a nitrogen atmosphere has been described. The product of carbonitrothermic reduction at $1475-1500^{\circ} \mathrm{C}$ comprises principally $\beta$ sialon and minor amounts of another phase in the Si$\mathrm{Al}-\mathrm{N}-\mathrm{O}$ system known as the $15 \mathrm{R}$ phase. The amount of each of these two phases strongly depends on reaction time. The colloidal stability behaviour of the ground carbothermal $\beta$-sialon in water was found to depend strongly on the $\mathrm{pH}$. Slip casting of the $\beta$-sialon powder from the suspension followed by sintering at 1500 to $1600^{\circ} \mathrm{C}$ resulted in compounds with densities ranging from 94 to $99 \%$ of the theoretical value. The particle size of the $\beta$-sialon influences the densification achieved during sintering. The use of yttria in amounts of 5 and $10 \%$ as an additive to $\beta$-sialon to obtain higher densities by sintering works well for relatively coarser powder.
\end{abstract}

\section{INTRODUCTION}

$\beta$-Sialon is based on the $\beta$ modification of silicon nitride in which aluminium partially replaces silicon and oxygen correspondingly replaces nitrogen. On account of its atomic arrangement, the physical and mechanical properties of $\beta$ sialon are similar to those of $\mathrm{Si}_{3} \mathrm{~N}_{4}$ and because of its composition, its chemical properties approach those of alumina $/ 1 / . \beta$-Sialon has high strength, good thermal shock resistance, resistance to corrosion and erosion and is superior to $\mathrm{Si}_{3} \mathrm{~N}_{4}$ in sinterability and oxidation resistance $12,3 /$. It is generally synthesised by reaction sintering or reaction hot pressing of pure $\mathrm{Si}_{3} \mathrm{~N}_{4}, \mathrm{Al}_{2} \mathrm{O}_{3}, \mathrm{AIN}$ and $\mathrm{SiO}_{2} / 4,5 /$. It is also possible to prepare $\beta$-sialon from a variety of naturally occurring materials like clay $16 /$, volcanic ash $17 /$, rice husk $/ 1 /$ and kaolin $/ 8 /$. The overall reaction for the preparation of $\beta$-sialon froni kaolin by carbonitrothermic reduction may be written as

$$
\begin{aligned}
& 3\left(2 \mathrm{SiO}_{2} \cdot \mathrm{Al}_{2} \mathrm{O}_{3} \cdot 2 \mathrm{H}_{2} \mathrm{O}\right)+15 \mathrm{C}+5 \mathrm{~N}_{2} \rightarrow \\
& 2 \mathrm{Si}_{3} \mathrm{AI}_{3} \mathrm{O}_{3} \mathrm{~N}_{5}+15 \mathrm{CO}+6 \mathrm{H}_{2} \mathrm{O}
\end{aligned}
$$

This reaction is thermodynamically favourable $/ 8 /$ but the reaction mechanism and end products obtained depend on factors such as impurities in the kaolin and carbon used for the reaction. The impurities accumulate in the only solid product of the reaction, $\beta$-sialon, and may affect subsequent processing of $\beta$-sialon to form dense components. The actual composition of kaolin shows minor variations depending on the location, and the present investigation is concerned with the Turkish kaolin as the starting material and the processing of $\beta$ sialon prepared from it.

\section{EXPERIMENTAL}

Two kinds of indigenous kaolin, designated $\mathrm{Ml}$ and M6 (Matel A.S., Bilecik Turkiye), and carbon (Elftex 125, Cabot) were used as starting materials. The 
analysis of these materials is given in Table 1. Calcium carbonate (Merck) was used as an additive to the kaolin-carbon charge to accelerate the carbothermic reduction.

Kaolin was dry milled in a hammer crusher. It was then mixed with calculated quantities of coal and calcium carbonate in a mixer. Water was then added as a binder and the damp powder was tumbled to obtain spherical granules which were sieved to separate a $>2$ $\mathrm{mm},<4 \mathrm{~mm}$ size fraction.

Experiments with small charges were carried out in a horizontal tube furnace (Heareus). The pellets were placed in an alumina tube (25 mm diameter) in a packed bed and reacted with nitrogen in different batches under nitrogen flow varying from 6.25 lph to $50 \mathrm{lph}$. The temperature was varied from 1400 to $1500^{\circ} \mathrm{C}$ and the reaction time from 0 to $12 \mathrm{~h}$.

Experiments with larger charges were carried out in a horizontal tube furnace which had a diameter of 50 $\mathrm{mm}$ and a hot zone length of $400 \mathrm{~mm}$ and was heated by silicon carbide elements (Carbolite, Sheffield, England). About $500 \mathrm{~g}$ of non-fractionized pellets were used as charge, nitrogen flow was $35 \mathrm{lph}$ and temperature was $1500^{\circ} \mathrm{C}$.

The products were examined at different stages of the reaction by X-ray diffraction. After synthesis of the $\beta$-sialon, the granules were dry-milled in a hammer crusher and then heated to $750^{\circ} \mathrm{C}$ for $4 \mathrm{~h}$ in an air sintering furnace to remove any residual coal. The product was then milled in an attrition mill (HOD 1, Union Process, 0.751 tefzel coated tank, $7 \mathrm{~mm} \mathrm{Si}_{3} \mathrm{~N}_{4}$ balls, with 5 and $10 \mathrm{wt} \%$ yttria as additive in some cases). Particle size and surface area were measured by using sedimentation and BET methods, respectively. Nitric acid or sodium hydroxide was added to the suspension to adjust the $\mathrm{pH}$. Sedimentation experiments were performed to determine the conditions for a stable colloidal suspension. Ammonium polyacrylate (Dolapix $\mathrm{CE}$ 64, Zschimmer and Schwartz) was used as a deflocculant and a varying amount of deflocculant was

Table 1

Analysis of raw materials used for $\beta$-sialon preparation

(Values in wt\% unless otherwise specified)

\begin{tabular}{|c|c|c|}
\hline & \multicolumn{2}{|c|}{ Kaolin } \\
\hline & M1 & M6 \\
\hline $\mathrm{Al}_{2} \mathrm{O}_{3}$ & 38.86 & 36.30 \\
\hline $\mathrm{SiO}_{2}$ & 48.14 & 47.36 \\
\hline $\mathrm{Fe}_{2} \mathrm{O}_{3}$ & 2.12 & 2.12 \\
\hline $\mathrm{MgO}$ & 0.41 & 0.43 \\
\hline $\mathrm{CaO}$ & 0.45 & 0.42 \\
\hline $\mathrm{Na}_{2} \mathrm{O}$ & 0.03 & 0.03 \\
\hline $\mathrm{K}_{2} \mathrm{O}$ & 0.33 & 1.38 \\
\hline $\mathrm{TiO}_{2}$ & 0.34 & 0.95 \\
\hline LOI & 9.32 & 11.01 \\
\hline$d_{s 0}(\mu \mathrm{m})$ & 0.49 & 0.31 \\
\hline \multirow[t]{2}{*}{ BET $m^{2} g^{1}$} & 21.17 & 17.10 \\
\hline & \multicolumn{2}{|c|}{ Coal (Elttex 125) } \\
\hline C & \multicolumn{2}{|c|}{$>98$} \\
\hline LOI & \multicolumn{2}{|c|}{$<0.1$} \\
\hline BET $m^{2} g^{-1}$ & \multicolumn{2}{|c|}{27} \\
\hline
\end{tabular}


added to the suspension with ultrasonic treatment $19,10 \%$. Slip cast tablets, $33 \mathrm{~mm}$ in diameter and $3 \mathrm{~mm}$ in thickness, were prepared on plaster of Paris moulds using a suspension containing $70 \mathrm{wt} \%$ of solid at $\mathrm{pH}$ 10.5. After slip casting, the tablets were dried at room temperature for $5 \mathrm{~h}$, then at $40^{\circ} \mathrm{C}$ for $10 \mathrm{~h}$ and at $100^{\circ} \mathrm{C}$ for $24 \mathrm{~h}$. The dried tablets were then sintered at 1500 to $1600^{\circ} \mathrm{C}$ for $2 \mathrm{~h}$ under nitrogen at 1 atm using a nitriding furnace ( $\mathrm{KCE}$, Germany).

\section{RESULTS AND DISCUSSION}

Carbonitrothermic reduction experiments on small charges carried out at different temperatures and nitrogen flow rates showed an optimum reaction temperature of $1475^{\circ} \mathrm{C}$ and a nitrogen flow rate of 12.5 lph. The composition of the products obtained at this temperature and flowrate for a $30 \mathrm{~g}$ charge of $>2 \mathrm{~mm}$ $<4 \mathrm{~mm}$ pellets prepared from $\mathrm{Ml}$ kaolin is shown as a function of reaction time in Fig. 1. When the pellets had reached $1475^{\circ} \mathrm{C}$, the reduction and nitridation had already started and approximately $9 \% \beta$-sialon had already formed. At the same time, the product contained a large amount (about 60\%) of mullite and other phases like $\mathrm{Al}_{2} \mathrm{O}_{3}, \mathrm{X}$-phase and $\mathrm{SiC}$. At the beginning of the reaction some $\mathrm{X}$-phase is formed which disappears after three hours. The maximum

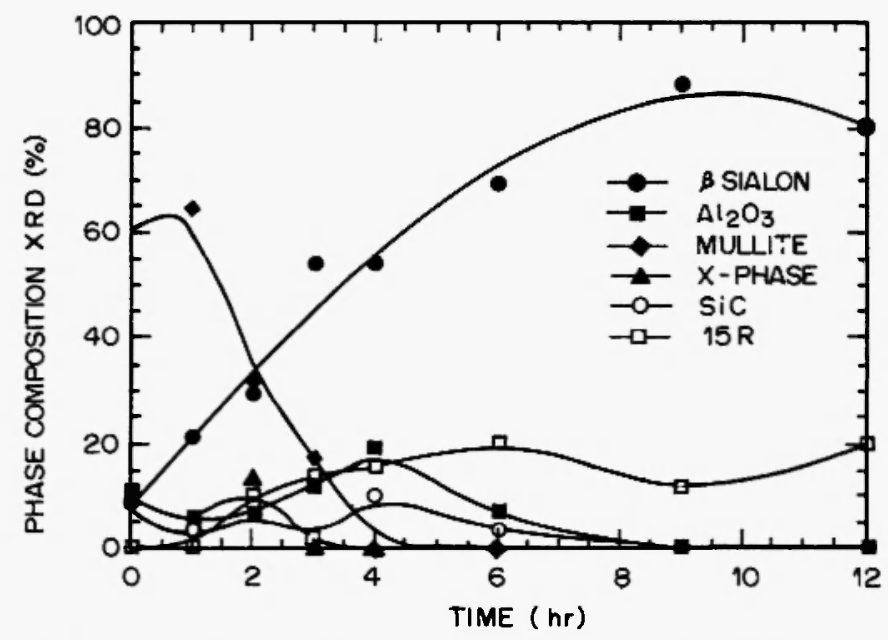

Fig. 1: Composition of the product as a function of the reaction time at $1475^{\circ} \mathrm{C}$ in a nitrogen flow of 12.5 lph (for M1 kaolin). sialon content of about $88 \%$ is reached after $9 \mathrm{~h}$ of reaction time, and the other component in the product is the $15 \mathrm{R}$ phase. If the reaction time is longer than 9 $h$, the $\beta$-sialon content of the product decreases and the $15 \mathrm{R}$ phase content increases.

The products formed during the course of reaction as shown in Fig. 1 generally conform to the known behaviour of kaolin on heating /8/. When kaolin is heated, at about $500^{\circ} \mathrm{C}$ dehydration occurs resulting in the formation of an amorphous material known as metakaolin and at $1200^{\circ} \mathrm{C}$ nucleation of mullite occurs. When the reaction temperature of $1475^{\circ} \mathrm{C}$ is reached, kaolin has already broken down to a mixture of mullite and pure silica and silica reacts with carbon to form silicon carbide, $\mathrm{SiC}$. The reactions may be represented as:

$$
\begin{aligned}
& 3\left(2 \mathrm{SiO}_{2} \cdot \mathrm{Al}_{2} \mathrm{O}_{3} \cdot 2 \mathrm{H}_{2} \mathrm{O}\right) \rightarrow \\
& 3 \mathrm{Al}_{2} \mathrm{O}_{3} \cdot 2 \mathrm{SiO}_{2}+4 \mathrm{SiO}_{2}+6 \mathrm{H}_{2} \mathrm{O}
\end{aligned}
$$

and

$$
4 \mathrm{SiO}_{2}+12 \mathrm{C}=4 \mathrm{SiC}+8 \mathrm{CO}
$$

Silicon carbide reacts subsequently with mullite to form $\beta$-sialon

$$
\begin{aligned}
& 3 \mathrm{Al}_{2} \mathrm{O}_{3} \cdot 2 \mathrm{SiO}_{2}+4 \mathrm{SiC}+3 \mathrm{C}+5 \mathrm{~N}_{2}= \\
& 2 \mathrm{Si}_{3} \mathrm{Al}_{3} \mathrm{O}_{3} \mathrm{~N}_{5}+7 \mathrm{CO}
\end{aligned}
$$

The products referred to as $\mathrm{X}$ and $15 \mathrm{R}$ in Fig. 1 are phases found in the $\mathrm{Si}-\mathrm{Al}-\mathrm{O}-\mathrm{N}$ behaviour diagram at high temperatures.

The products obtained in the carbothermic reduction of kaolin to $\beta$-sialon are influenced by the constituents in the kaolin and their relative concentration. This is brought out by the results of larger scale experiments. A product containing $85 \%$ of $\beta$-sialon and $15 \%$ of $\mathrm{R}$ is obtained by reacting $500 \mathrm{~g}$ of the $\mathrm{Ml}$ pellets at $1500^{\circ} \mathrm{C}$ for $28 \mathrm{~h}$ in a nitrogen flow of $35 \mathrm{lph}$. At the same temperature and nitrogen flow, $95 \%$ of $\beta$ sialon and $5 \%$ of $15 \mathrm{R}$ is produced using $\mathrm{M} 6$ pellets for $25 \mathrm{~h}$.

The attrition milling curve of carbon removed $\beta$ sialon product is shown in Fig. 2. Even though $8 \mathrm{~h}$ of attrition milling was applied to both $\beta$-sialon $(\mathrm{Ml}$ and 


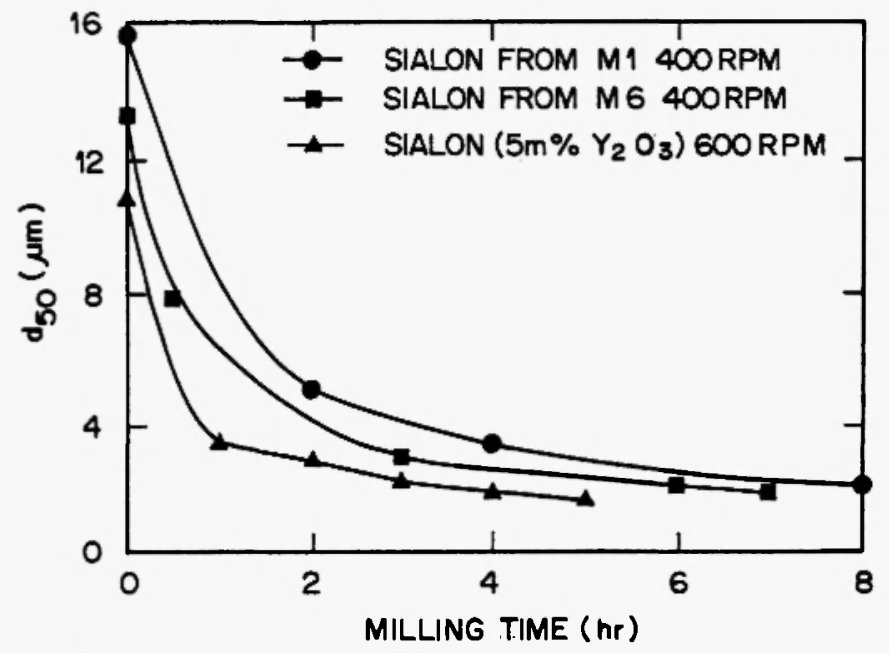

Fig. 2: Attrition milling curve for $\mathrm{Ml}$ and $\mathrm{M} 6 \beta^{\prime}$ sialon powders.

M6) powders, they could not be milled to submicron size. To obtain smaller particle size, a higher rotation speed was also tried during attrition milling. The $d_{50}$ value indeed decreased and was determined as $1.65 \mu \mathrm{m}$ after $5 \mathrm{~h}$ of attrition milling at $600 \mathrm{rpm}$.

The results of sedimentation experiments are presented in Figs. 3 and 4. Fig. 3 shows that the sediment volume for diluted suspensions, obtained after several weeks, is lowest indicating the lowest degree of flocculation, i.e., highest degree of stability at $\mathrm{pH} 10-$ 11. The effect of deflocculant addition on sedimentation at $\mathrm{pH} 10.5$ is shown in Fig. 4. It may be seen that

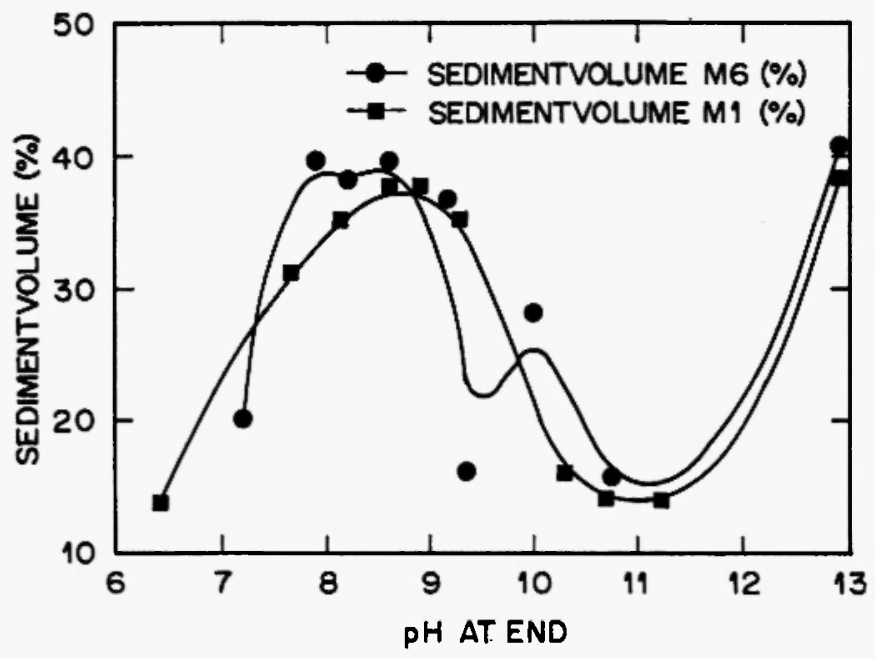

Fig. 3: Sediment volume as a function of $\mathrm{pH}$ for diluted $\beta$-sialon suspension.

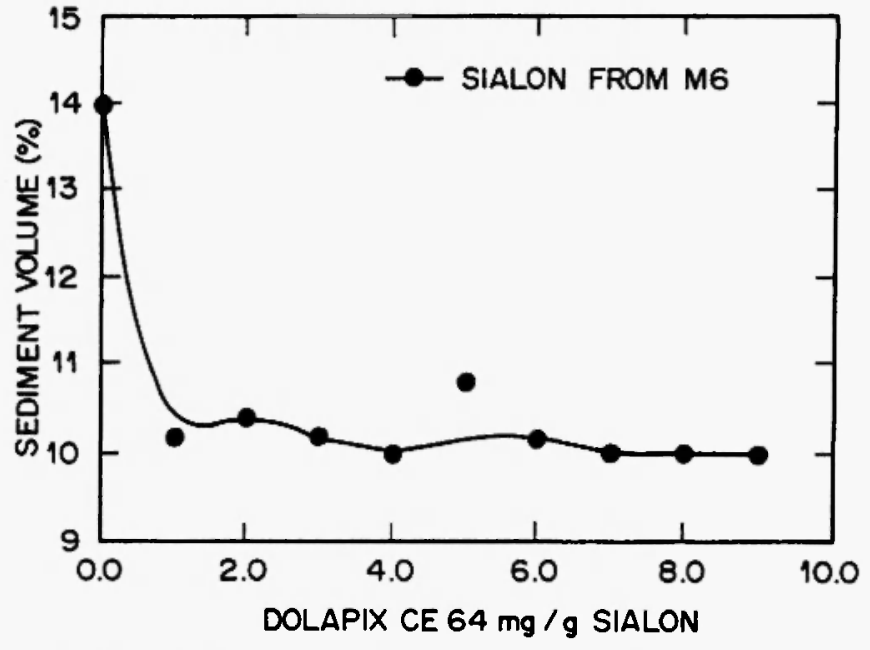

Fig. 4: Sediment volume as a function of deflocculant concentration for diluted $\beta$ sialon suspension.

addition of more than $1 \mathrm{mg}$ Dolapix/g of sialon has no significant effect on the sediment volume.

The sintering experiment on dried slip cast tablets prepared from coarser powder (milled at $400 \mathrm{rpm}$ for 4 h) and containing $5 \mathrm{wt} \% \mathrm{Y}_{2} \mathrm{O}_{3}$ was carried out at $1500^{\circ} \mathrm{C}$ for $2 \mathrm{~h}$. This resulted in a density of $3.03 \mathrm{~g} \mathrm{~cm}^{-}$ ${ }^{3}$ (Prel $=94 \%$ ). Increasing the sintering temperature to $1550^{\circ} \mathrm{C}$ and $1600^{\circ} \mathrm{C}$ improved the density to $3.14 \mathrm{~g} \mathrm{~cm}^{-3}$ ( $P_{\text {rel }}=97.5 \%$ ) and $3.15 \mathrm{~g} \mathrm{~cm}^{-3}$ ( $\rho_{\text {rel }}=97.82 \%$ ). Under similar conditions tablets containing $10 \mathrm{wt} \%$ yttria reached densities of $3.11 \mathrm{gm} \mathrm{cm}^{-3}$ ( $\rho_{\text {rel }}=94.81 \%$ ), 3.18 $\mathrm{g} \mathrm{cm}^{-3}$ ( $\left.p_{\text {rel }}=96.95 \%\right)$ and $3.24 \mathrm{~g} \mathrm{~cm}^{-3}$ ( $\left.\rho_{\text {rel }}=98.78 \%\right)$ 1550 and $1600^{\circ} \mathrm{C}$, respectively. Tablets prepared from fine powder (milled at $600 \mathrm{rpm}$ for $5 \mathrm{~h}$ ) containing 5 and $10 \mathrm{wt} \% \mathrm{Y}_{2} \mathrm{O}_{3}$ were sintered at $1600^{\circ} \mathrm{C}$ for $2 \mathrm{~h}$. The density of tablets containing $5 \mathrm{wt} \% \mathrm{Y}_{2} \mathrm{O}_{3}$ was $3.13 \mathrm{~g}$ $\mathrm{cm}^{-3}$ ( $p_{\text {rel }}=97 \%$ ). The tablets containing $10 \mathrm{wt} \% \mathrm{Y}_{2} \mathrm{O}_{3}$ cracked due to evaporation of gaseous products. There was approximately $9 \%$ weight loss in these samples.

Ball on ring test was applied to samples which contained $5 \mathrm{wt} \% \mathrm{Y}_{2} \mathrm{O}_{3}$ and had been sintered at $1600^{\circ} \mathrm{C}$. Average BOR strength was $182 \pm 42 \mathrm{MPa}$ ( $\mathrm{n}=$ 11).

\section{CONCLUSIONS}

Starting from two varieties of Turkish kaolin, $\beta$ 
sialon has been prepared by carbonitrothermic reduction at $1475^{\circ} \mathrm{C}$. The reaction proceeds through the formation of mullite and silicon carbide and an $\mathrm{X}$ phase, all of which disappear in about $8 \mathrm{~h}$ of reaction time and only $\beta$-sialon and a $15 R$ phase remain. Depending on the kaolin used, the product contains 85 to $95 \% \beta$-sialon and the remainder is $15 R$.

The $\beta$-sialon product obtained could be milled to micron size powder but not to submicron size even after $8 \mathrm{~h}$ of attrition milling. The colloidal stability of the suspension prepared from milled powder is strongly $\mathrm{pH}$ dependent, the stability being highest at $\mathrm{pH} 10-11$. Slip cast tablets prepared from this suspension, with 5 to $10 \%$ yttria, could be sintered to high densities at 1500 to $1600^{\circ} \mathrm{C}$ in a nitrogen atmosphere. The densities range from 94 to $-99 \%$ of the theoretical value. The particle size of the $\beta$-sialon influences the densification achieved during sintering. The $10 \% \quad \mathrm{Y}_{2} \mathrm{O}_{3}$ as an additive works well with relatively coarser powder, resulting in nearly $99 \%$ of theoretical density after sintering for $2 \mathrm{~h}$ at $1600^{\circ} \mathrm{C}$.

\section{ACKNOWLEDGEMENT}

The study described here was made possible by financial support from the United Nations Industrial Development Organisation (UNIDO). The authors are grateful to Prof, R. Metselaar for helpful discussions and advice.

\section{REFERENCES}

1. K.H. Jack, Sialons, in: Encyclopaedia of Materials Science and Engineering, M.B. Bever (ed.), Pergamon, Oxford, Vol. 6, 1986; p. 4385.

2. S. Dutta, Am. Ceram. Soc. Bull., 59, 623-625, 634 (1980).

3. M. Mitomo, N. Kuramoto and Y. Inomata, $J$. Mater. Sci., 14, 2309 (1978).

4. K.H. Jack, The crystal chemistry of the sialons and related nitrogen ceramics, in: Nitrogen Ceramics, F.L. Ritcey (ed.), Noordhoff International, Leyden, The Netherlands, 1976; p. 109.

5. M.H. Lewis, B.D. Powell and P. Drew, The formation of single phase Si-Al-O-N ceramics, in: Nitrogen Ceramics, F.L. Ritcey (ed.), Noordhoff International, Leyden, The Netherlands, 1977; pp. 12,61 .

6. J.G. Lee and I.B. Cutler, Am. Ceram. Soc. Bull., 58, 869 (1979).

7. S. Umebayashi, Direct preparation of sialon type materials from naturally occurring minerals, in: Nitrogen Ceramics, F.L. Ritcey (ed.), NATO Advanced Study Institutes Series: Applied Sciences, Noordhoff International, Leyden, The Netherlands, 1977; p. 323.

8. I. Higgins and A. Hendry, Br. Ceram. Trans. J., 85, 161 (1986).

9. D. Kicevic, H. Schubert and G. Petzow, Colloidal processing of sialon ceramics, Proceedings ECERS'II, VI, 349 (1991).

10. M.J. Hoffmann, A. Nagel, P. Greil and G. Petzow, J. Am. Ceram. Soc., 72, 765 (1989). 
